\title{
Classroom Discourse Analysis: A Case of ESL Reading Class
}

\author{
Nurtimhar Adil Shahaji \\ Southern City Colleges and Western Mindanao State University, Philippines \\ eunjinur@gmail.com
}

DOI: http://doi.org/ 10.36892/ijlls.v3i2.368

\begin{tabular}{|c|c|}
\hline $\begin{array}{l}\text { Received: } \\
\text { 01/08/2020 }\end{array}$ & $\begin{array}{l}\text { Abstract } \\
\text { More than the recognition, perception, and interpretation of written materials, }\end{array}$ \\
\hline $\begin{array}{l}\text { Accepted: } \\
\text { 01/05/2021 }\end{array}$ & $\begin{array}{l}\text { reading has been dubbed as our bridge to other skills that are necessary for } \\
\text { academic success. Subsequently, one way for teachers to monitor both the } \\
\text { quantity and quality of output of the students is through Classroom discourse } \\
\text { analysis, which is an aspect of classroom process research (Jiang, 2012). This }\end{array}$ \\
\hline $\begin{array}{l}\text { Keywords: } \\
\text { Classroom discourse } \\
\text { analysis, Schemata, } \\
\text { Teacher's } \\
\text { questioning. }\end{array}$ & $\begin{array}{l}\text { paper, therefore, aimed to determine teacher's questioning vis-à-vis students' } \\
\text { reading strategies in the case of an ESL reading class in one of the private } \\
\text { schools in Zamboanga City, Philipenese through classroom discourse } \\
\text { analysis. As a qualitative endeavor, it made use of classroom observations } \\
\text { with the aid of an audio recorder to enable the analysis. A total of } 131 \\
\text { exchanges were generated in a 45-minute discussion, with roughly } 25 \text { minutes } \\
\text { allotted to the said discourse, and the rest for other activities. Teacher-Pupil- } \\
\text { Teacher (TPT) captured as Teacher-Student-Teacher (TST) in the case of this } \\
\text { paper, is the recurring sequence during the whole duration of the discourse. } \\
\text { Discourse analysis that was done to an audio recording transcript of a } \\
\text { reading class observation revealed patterns that are primarily present in } \\
\text { some, if not most, discourse analysis (DA) research literature. Interestingly, it, } \\
\text { however, uncovered the following: for teacher's way of questioning (in this } \\
\text { case, echoice and epistemic), epistemic questions (mostly, rhetorical for this } \\
\text { matter), were made reference(s) by the students in answering questions. } \\
\text { Consequently, the lesson or activity became, to some extent, communicative, } \\
\text { because of the above mentioned points. }\end{array}$ \\
\hline
\end{tabular}

\section{INTRODUCTION}

Generally, reading comprehension can be defined as "the ability to understand information in a text and interpret it appropriately" (Akbari, 2014, p. 122). Consequently, teaching reading is as complex as the reading itself. The understanding of complex reading process and the ability to use a wide array of teaching approaches are evidence of effective teachers, which yield "confident and independent readers" (Professional Development Services for Teachers, p.2). More than the recognition, perception, and interpretation of written materials, reading has been dubbed as our bridge to other skills that are necessary for academic success. Subsequently, one way for teachers to monitor both the students' quantity and quality of output is through Classroom discourse analysis, which is an aspect of classroom process research (Jiang, 2012). Cook (1989) defined discourse as the "language in use" (p.9) and the analysis of the language in use refers to us as discourse analysis (Brown \& Yule, 1983, p. 1). On account of this, discourse analysis involves looking at the language form and language function; thus, it identifies linguistic features that depict various genres and social and cultural factors that assist our interpretation and understanding of manifold of texts, as well as types of talks (Jiang, 2012).

\section{LITERATURE REVIEW}




\subsection{Discourse analysis in the classroom}

In the language of Gee (1999a), beyond just a talk, discourse embraces any meaningful use of language and communicative gestures as well. Information on two of the primary functions of language can be sourced out by looking closely into the discourse: "to support the performance of social activities and social identities, and to support human affiliation within cultures, social groups, and institution" (Gee, 1999, p.1). Hence, intimately, discourse is consistent with: the presentation of social activities (e.g. classroom lessons), the formation and as well the maintenance of social identities, the interactions of social groups, and the setting up of social institutions. Discourse analysis provides an insight about the way things are in a certain circumstance.

One of the most common models of discourse analysis is the Sinclair and Coulthard Classroom discourse analysis. Sinclair and Coulthard's (S\&C) 1975 method of discourse analysis (DA) has been described as 'a litmus test for whether or not a lesson is communicative' (Raine, 2010, p. 19, as cited in Cockayne, 2010). Sinclair and Coulthard's Model consists of five ranks: lesson; transaction; exchange; move and act. The highest rank in this model was the lesson, but they were unable to show structurally how a lesson is made up of transactions (Coulthard, 1985, p. 123 as cited in Heinel, 2017). The other four ranks, on the other hand had well defined structure. Transactions were made up of exchanges, exchanges were "expressed in terms of moves", and moves consisted of "one or more acts" (Coulthard, 1985, p. 124-125). There are two (2) major classes of exchange as indicated by Sinclair and Coulthard (1992) in their model: boundary exchange and teaching exchanges (p.25). The former typically signals the beginning or the end of a lesson, transaction, or a change of topic normally marked by words such as 'right', 'alright', 'now', and 'OK', either with falling or rising intonation and a short break (Sinclair \& Coulthard, 1992 as cited in Heinel, 2017). On the other, the latter is described as "the individual steps by which the lesson progresses" (Ibid).

Teaching exchanges consist of a minimum of one move and a maximum of three: a required opening move, followed by a possible answering move, and consequently a probable follow up move (Cook, 1989 quoted in Heinel, 2017), and Sinclair and Coulthard (1992) also termed these as Initiation (I), Response (R), and Feedback (F) (p.26), and these are used to express structure of exchange. Typically, move, in an exchange pertains to the minimal contribution of a speaker (to make an exchange) (Coulthard, 1985, p. 125 quoted in Heinel, 2017). In the said model, Initiation (I) moves are created by the teacher, and occasionally followed by a student (verbal or non-verbal) response (R) moves. Afterwards, response (R) moves are followed by some kind of a Feedback or Follow-up (F) move which is made by the teacher in order to accept, reject, evaluate or comment on the response made by the students (Hellerman, 2003, p. 80 as cited in Heinel, 2017).

Generally, discourse analysis refers to structural analysis in macro and as well as micro views (Chang, 2017). The first phase, which is the macro analysis, refers to the surface understanding in English reading comprehension. On the other hand, micro analysis involves the analysis of vocabulary, grammar, cohesion and information structure. Both of the analysis phases are crucial in the discourse analysis.

\subsection{Schemata and Meaning-making}

Consideration of the different facets in addition to the task of reading by students who have already established a schema in relation to the topic in another tongue or speech must be noted by language teachers (Landry, 2002). McCarthy (1991) quoted in (Landry, 2002) put schemata as "the underlying connections that allow new experiences and information to be aligned with previous knowledge" (p.168). Further, logical relationships are necessary to make sense out of a text. By the same token, there are three types of schemata: content, formal, and abstract. Content schemata refers to evident relationships, obvious from 
a topic; formal, this refers to distant connections based on understanding of generalizations and mindset, and; abstract, involves hidden factors and thematic consideration.

Faulty or inaccurate constructs usually resulted from the absence of schema or the inability to activate it (Carrell \& Eisterhold, 1983, in Carrell, et al, 1998, p.85) in (Landry, 2002).Further, benefits from either being more prepared for a text or the text itself could be modified for easier comprehension are expected of the readers (Carrell \& Eisterhold, 1983, in Carrell, et al, 1998, p.85); however, it is arguable whether text modification aids in the long term or forces learners to use immature strategies for reading (Landry, 2002).

Dichotomous views on schemata have to be considered as well. On one hand, a strong view perceives schemata as something that influences the opinion of the readers prior to reading a text or selection (Landry, 2002). Van Djik (1981) puts schemata as higher-level complex knowledge structures (p.141) that operate as what Anderson (1977) termed "ideational scaffolding". On the other hand, weaker views state that schemata are structured background knowledge on a topic leading to predictions of discourse; independently, messages are perceived in a particular manner determined by the following: person's history, interests, gender, excreta (Anderson et al., 1977). Moreover, Bartlett (1932) viewed memory as constructive and mental representation was built from current discourse and background knowledge; hence, memory is developed from organized pieces by way of schema's nature as an active feature. Furthermore, fixed or flexible schemata are a way to account for interpretation and production of discourse ( (Brown \& Yule, 1983) in (Landry, 2002).

In the language of Anderson \& Pearson (1984); Bernhardt (1991), Carrell, (1991); Grabe, (1991); Rumelhart, (1980) as quoted in (Maarof \& Yaacob, 2011), in the process of reading, reader is an active participant, constructing meaning from clues found in printed texts (p.211). Thus, meaning is not intrinsic aspect of the text; rather, "texts have the potential for meaning" (Widdowson, 1984).

\section{RESEARCH QUESTIONS}

This paper is aimed at discovering patterns of interactions in an ESL reading class accounting for the teacher's questioning strategies, and as well as learners' reading strategies as disclosed through discourse analysis.

\section{METHODOLOGY}

The paper subscribed to qualitative design of research specifically, discourse analysis. A single case of a highschool reading class was the unit of analysis of the paper; permissions were importantly sought from the principal and consequently, of that of the teacher handling the reading class. An audio recorder was utilized to record the conversations during the reading class. Similarly, the researcher also took observational notes in order to record the explicit behaviors of the learners during the event.

\section{ANALYSIS}

\section{The Reading class observation}

Previously, important concepts were put forward in the light of the subsequent analysis. The reading class observation was done at Southern City Colleges. Audio recorder was used in order to capture the conversation that was to be transcribed in order to discover patterns, hence, phenomenon, eventually, that might have occurred

In brief, a total of 131 exchanges were generated in a 45-minute discussion, with roughly 25 minutes allotted to the said discourse, and the rest for other activities. TPT, or Teacher-Pupil-Teacher (Teacher-Student-Teacher, in the case of this paper) is the recurring sequence during the whole duration of the discourse. Teacher dominated the discourse. 
Sinclair and Coulthard (1975) as cited in Jiang (2012), established that TPT is a regular sequence in the classroom discourse.

In recapitulation, the teacher had an assigned reading which is a novel by Brazilian lyricist and novelist, Paulo Coelho, titled Brida. One (1) week time, as evident in the transcript, was allocated to the students to read the said novel. The instruction was that a discussion would be done after the students read the novel, and active participation was quite expected as always.

In the course of this analysis, themes and concepts would follow and be given explications (along with the excerpts from the transcript) and these were grounded on the observed phenomenon. An important highlight of this analysis, which is very crucial to every language teaching, and specifically, teaching reading, is the art of questioning employed by the teacher. Strategies, if there were any being employed by the students, would be determined as well, though meaning is always constructed subjectively by those who engaged in the discourse, researcher who analyzes discourse also brings his own subjective interpretations and meaning constructions to the discourse $\mathrm{s} /$ he analyzes.

At the beginning, the teacher set the mode before proceeding with the discussion. It was necessary because it could serve as some sort of an activation of the previous knowledge for the reason that the students might have forgotten what's to be done on that day or the other way around. However, it would be logical enough that even if the teacher did not do that, students still have to be responsible with the task they were assigned with.

\section{Teacher's questions in the discussion}

Basically, the reading teacher, during the event was asking questions that were really geared toward the context of the discussion. Comprehension questions were the dominant questions of the teacher, as evident in the transcript. Cognitively, in Bloom's Taxonomy, comprehension questions basically encompass understanding usually of the facts and ideas by organizing, describing, interpreting, translating, and stating (general concepts). Teachers can check comprehension by asking their students open-ended questions, having them justify answers, or by collecting summaries (Landry, 2002).

In the same way, in teacher talk or teacher speech simplification is said to make input or language addressed to learners more accessible (Lynch, 1996); hence, it is generally lexically and syntactically less complex (Vivekmetakorn \& Thamma, 2015). Furthermore, questions are utilized to check students' comprehension and encourage interaction between students and teachers or among themselves" (Ibid).

Teacher: $\quad$ Okay... Brida.... So, anyone? Who could give me... ahm... a little bit of an overview of what... ahm, Brida is.... Actually is? So... anyone? Who could give me a little summary of it? Or what is the gist of the novel by Paulo Coelho, Brida.... Okay... anyone? Okay Jenny...

At the beginning of the discourse, the teacher started to ask question (s) eliciting an overview, summary or the gist of the selection from the students. Consequently, a student answered and provided a direct answer to the question. At this point, it was hard to determine whether the student read the selection or the other way around. However, in the transcript the student mispronounced the word "quest" and as well as "magus", having pronounced it as "magnus". It might suggest that the student did not comprehend the selection and rather relied on the available summary of the story. Conversely, this concurs well enough with Cohen et al (1979) that inessential unknown vocabulary words disrupt comprehension unless the reader recognizes that they can be ignored. Strategy is an integral part of learning, more relevant than specific linguistic knowledge. How readers solve problems is a better focus than looking at what is problematic for them (Cohen et al. 1979 in (Landry, 2002).

In each episode, the teacher directed the discussion by remarking on student responses and asking supplementary questions. Each question set off a question-answer-comment cycle. At the beginning of the first episode, the teacher set the context by repeating the question 
several times. This focused the students' attention and let them know (from their previous experiences with this teacher) that they were expected to know the answer.

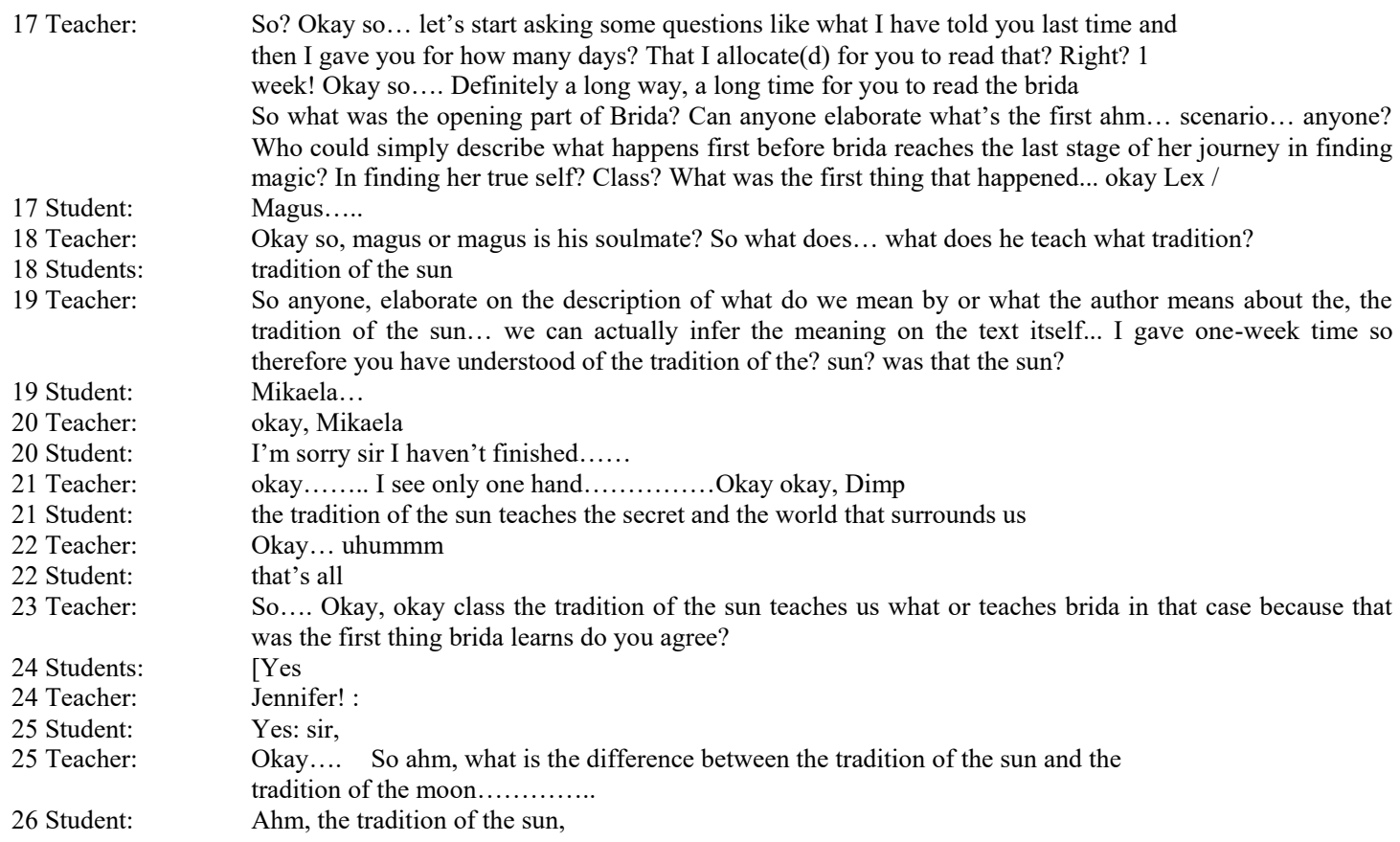

For the numbered 18 of teacher's turn, it was clear that the teacher was kind of revealing (asked a question but answered it anyway, though it may not be necessarily the direct answer), Long and Sato (1983) developed the classification of questions. In the said classifications, questions are categorized into echoic and epistemic questions. The former are mainly questions that ask for the repetition of an utterance or a confirmation that the utterance has been interpreted as intended, and these are utilized for comprehension checks, confirmation checks, and clarification requests. The latter, on the other hand, are questions that serve the purpose of acquiring information (Long \& Sato, 1983 in Vivekmetakorn \& Thamma, 2015).

\section{Schemata in Reading}

As evident in the transcript of the discourse, it can be inferred that the students in the class mainly applied schemata as a reading strategy when they approached the given text. Aside from that, meaning-making was also clearly found. It was possible that not all of the students in the class did the reading of the selection. Some of them, when asked a particular question, answered profoundly, that is, they were able to state (an) answer(s) but did not seem to really have understood their own response.

\footnotetext{
14 Teacher:

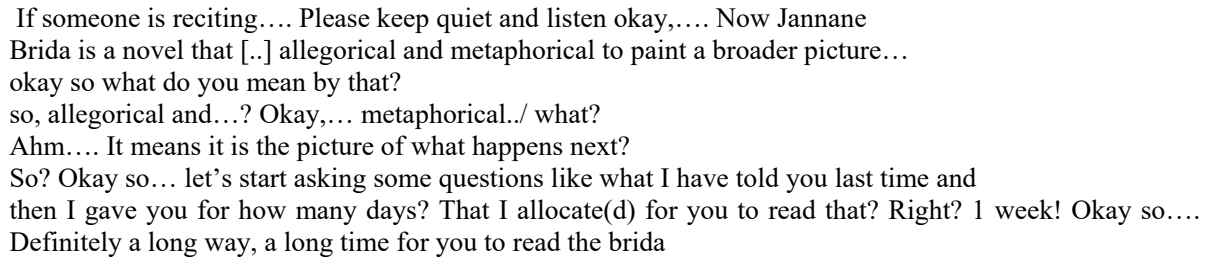

In the same way, the students seemed to make meanings out of every feedback and/or follow up of the teacher. Readers, as active participants construct meaning (s) from clues that are found in the printed text; hence, to put it another way, meaning is not necessarily found in the texts but the texts have the potential for meaning (Widdowson, 1984 in Maarof \& Yaacob, 2011). At this point, the students were not actually looking or reading the selection 
itself, but relied heavily on the unpremeditated narration of some part of the selection by the teacher.
42 Teacher:
So definitely they did that because it's parts of the tradition... Okay so
40 Students:
43 Teacher:
41 Student:
can anyone give an unforgettable quote from magus to brida?
44 Teacher:
gus $/ / \ldots \ldots . .$. Sir I have an idea
Okay
Magus says to ahm brida that... ahm be happy
Okay so (chuckles) Brida is a great novel and there a lot of quotations that you could get
So it pays, it really pays you if you really read thru the novel because it is something that can motivate you. Give you a glimpse of what life is what destiny is and fates Especially you guys at your stage you'll definitely learn from this novel (being relative to the real-life situation)
45 Teacher:
46 Teacher:
Aside from that........... So how has the brida ended? Or how does the story or the novel brida end?
42 Students:
Did she really ahm, find out what she was finding out?
Ishe live happily ever after

In this excerpt, the teacher was asking the students to give or cite an unforgettable quote from the characters. A student tried to answer but ended up just trying to give a guess. Clearly, it can be inferred that the student did not get or might not have read the selection after all. As indicated, the student might have just relied on the context of the story for the answer as the teacher revealed ideas and happenings in the novel.

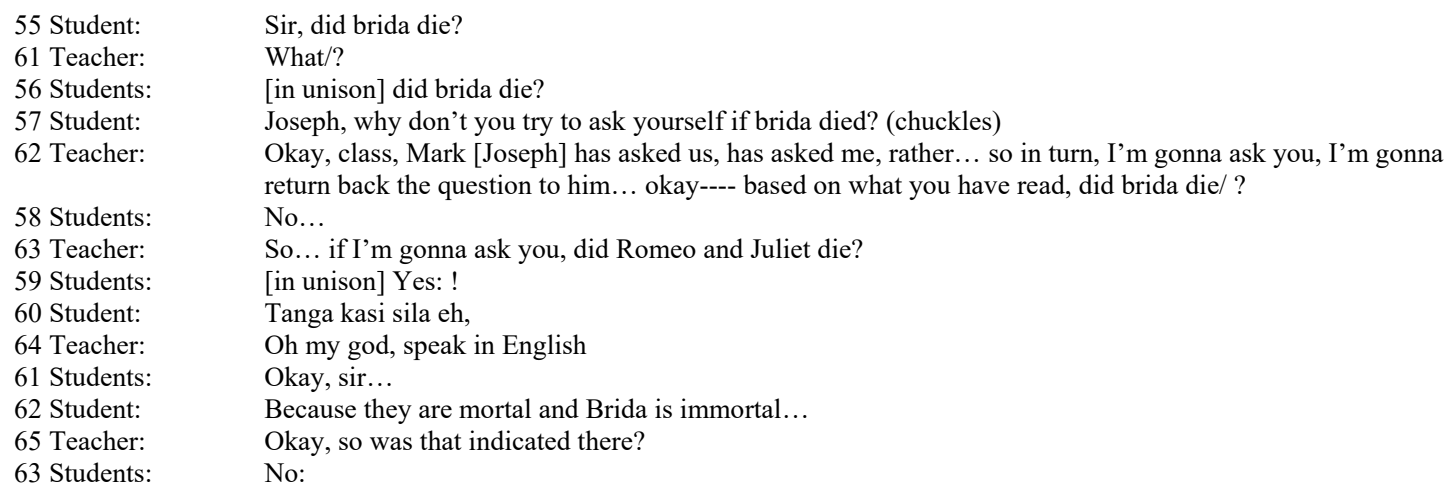

In the discourse part above, it's indicated that it's already the student who was asking a question to the teacher. On the part of the teacher, it was unusual at this point since the student were expected to have known of it, yet the teacher did not answer the question; instead, the teacher had the question answered by another student. The students answered "no". Now, by the same token, the teacher asked the students if Romeo and Juliet died, which was actually totally not included in the story. When the teacher was asked why did she ask the question, she said that it was to know whether the students have it as a link or something that served as their basis for answering, which was quite vague, so to speak. Furthermore, this might be in line with the finding that reading a great deal of different material for different purposes, a reader can "achieve the capacity for creating, refining, and connecting diverse arrays of cognitive schemata" (Grabe, 1986, p. 36 in Landry, 2002). Significantly, a student made a justification of the answer by saying that they [Romeo and Juliet] were mortal while Brida was immortal. Ausubel (1963, 1968 in Anderson, Spiro, \& Anderson, 1977) in his language, said that, “... new ideas and information are learned and retained most efficiently when inclusive and specifically relevant ideas are already available in cognitive structure to serve a subsuming role or to furnish ideational anchorage" (1968, p. 153).

33 Teacher:

34 Students:

34 Teacher:

35 Teacher:
Okay, so more than once right so... Another thing that I really wanna ask you about what you have read about the text brida okay so ahm brida thinks that she is a witch right is she yes? Definitely because that is why she wants to learn, with the guidance or with the help of magus teachers of which is one of those is magus... Wicca so what... what was the experience of brida, the most compelling experience that she had during her journey to finding magic to learning magic? With magus, Sir what is compelling

The one that is very, you know, that leaves you a great impact one that really compels you What was the most exciting part of part of her journey, like there are a lot of journeys 
there are a lot of paths that brida and magus have come across although Magus already knew that he really wanted brida to experience those things so... anyone? Who can give us the most compelling... Anyone? During her journey in finding is she really was her destiny

\footnotetext{
14 Teacher: If someone is reciting.... Please keep quiet and listen okay,.... Now Jannane

15 Student: $\quad$ Brida is a novel that [..] allegorical and metaphorical to paint a broader picture...

15 Teacher: okay so what do you mean by that?

16 Teacher: $\quad$ so, allegorical and...? Okay,... metaphorical../ what?

16 Students: $\quad A h m . .$. It means it is the picture of what happens next?
}

On one part of the discourse, it was obvious that the class was implementing an English Only Policy. Interestingly, based on the transcript it could be noted that students in this class were not really doing well in the English language (although it could only be furthered by a content-specific observation, that is, when its focus is on English speaking skills [of the students]). Not all of the students participated in the discussion; only a few students contributed to the exchange.

Another point was that there were words, though can be considered as basic vocabulary words, were mispronounced, but it's not necessarily a big issue in this analysis; however, mispronunciation and lack of vocabulary are possible hindrances to comprehension. In fact, Alderson (2000); Alderson et al., (2015); Grabe (2009); Jeon \& Yamashita (2014); (Koda) 2005 in Brevik, Olsen, \& Hellekjær (2016), found that vocabulary knowledge is indispensable for good reading comprehension. Moreover, when problems are present such as unfamiliar words or concepts, good readers "they deal with inconsistencies or gaps as needed" when trying to determine the meanings in the text (Duke et al., 2011, p. 56).

\section{DISCUSSION}

Mustapha (1995) puts reading as a multileveled, interactive, and hypothesisgenerating process in which readers construct a meaningful representation of text by using their knowledge of the world and of language.

With the data generated through the observation transcript, the analysis focused on the questioning of the teacher and as well as the strategy(ies) employed by the students in reading the given selection. Discourse analysis was done to the audio transcript of the reading class observation in order to find out some patterns and describe any occuring phenomenon in the said class.

It was found out that the teacher primarily utilized a combination of echoic and epistemic questions, as put forward by Long and Sato (1983). The former are mainly questions that ask for the repetition of an utterance or a confirmation that the utterance has been interpreted as intended, and these are utilized for comprehension checks, confirmation checks, and clarification requests. The latter, on the other hand, are questions that serve the purpose of acquiring information (Vivekmetakorn \& Thamma, 2015). Specifically, for echoic, comprehension checks, clarification requests, and confirmation checks were evident. For epistemic, the most prominent was rethorical because the teacher predominantly asked for effect only, maybe because of the fact that the students were not, to some extent, answering and just remained silent. Another pattern is about the reading strategy of the students. It is clear that the students mainly relied on the schema (maybe their strategy to approaching the given selection). For this observation, though it is in anyway clear that some of the students seemed to have not read the selection fully as it appeared in the transcript, their strategy, i.e. banking on the epistemic questions (e.g. rethorical) and feedback of the teacher, allowed them to at least make inferences (backed up to some point by the ideas that they got, probably when they read) about the story.

I also have to note that based on my observation, some students' inability to comprehend the text (which is a novel), can be attributed to Structural deficit hypothesis which claims that lack of grammatical knowledge or of processing ability interferes with 
higher level text comprehension (Stein, Cairns \& Zurif, 1984; Bowey, 1986a, 1986b; Bentin, Deutsch and Liberman, 1990; Menyuk et al., 1991; Scarborough, 1991 in Akbari, 2014). Syntactic awareness is also believed to assist readers in accomplishing their reading comprehension tasks effectively (Ibid.) Akbari's (2014) finding indicates that it may be argued that "grammatical knowledge predicts better comprehension and may be used as an indicator of success in reading"(p.125). However, in this case, further and specific inquiry has to be done yet. I have raised this assumption based on how students answered in the discussion.

In connection with Sinclair and Coulthard CDA, this discourse somehow fitted the model, given that the teacher predominantly did the talking, and it supports the findings of Vivekmetakorn \& Thamma (2015) that Initiation-response-feedback interaction pattern (I-RF) was the most recurring pattern and "teacher's questions served to initiate much of the talk in classroom"(p.63). The predominance of IRF pattern in the discourse certainly means that the discourse was teacher-centered. The class, however, was "communicative" only to an extent: probably because the students, albeit and obviously had little comprehension of what they read, were able to get into play by referencing with the epistemic questions of their teacher to recover and generate ideas and inferences, respectively.

\section{CONCLUSION}

This discourse analysis that was done to an audio recording transcript of a reading class observation found patterns that are primarily present in some, if not most, DA research literature. Interestingly, the analysis, however, uncovered the following: for teacher's way of questioning (in this case, echoic and epistemic), epistemic questions (mostly, rethorical for this matter), were made reference(s) by the students in answering questions. This was also true with the feedback of the teacher to each and every raised question; another was that schema served as their strategy to both (probably) approaching the text, and as well as during the discussion. Consequently, the lesson or activity became, to some extent, communicative, because of the abovementioned points.

Furthermore, it is put forward that schemata is relatively important in any reading activities, and appropriate and sufficient schema should be given to the students. Aside from that, it should be noted that questions generation should always be in line with the students' level of understanding. However, the level of the students' understanding is not always the issue and we should not let that cloud our thinking. From the analysis above, it will always be best for teachers to teach reading strategies to students so that they will be guided enough whenever they encounter problems along the way. Students who received instruction on reading strategies along with being taught the reading texts proved to be more proficient readers than those who did not (Sattar \& Salehi , 2012). Although the given selection was written perhaps in a manner that can be grasped by layreaders, it is important to note that it's still a novel, and aside from its length, syntactic complexity is always present. Possessing linguistic knowledge at sentential level would not suffice, yet necessary; having enough control over different lengths of texts and ability to deal with them applying appropriate strategies to those texts is what the learners need (Ibid.) Finally, it all boils down to the fact that reading teachers should strike a balance between how to read and what to read when teaching reading to students.

\section{REFERENCES}

Akbari, Z. (2014). The role of grammar in second language reading comprehension: Iranian ESP context. Procedia Social and Behavioral Sciences, 98, 122-126. Retrieved August 2019, from www.sciencedirect.com 
Alsubaie, S. (2015). An analysis of classroom discourse: Elicitation techniques in EFL classrooms. International Journal of English Language Teaching, 3(8), 29-39.

Anderson, R. C., Spiro, R. J., \& Anderson, M. C. (1977). Schemata as scaffolding for the representation of information in connected discourse. Technical Report, University of Illinois at Urbana Champaign, Center for the Study of Reading.

Armbruster, B., Lehr, F., \& Osborn, J. (2001). Put reading first: The research building blocks for teaching children to read. Washington, DC: The U.S. Department of Education.

Brevik , L. M., Olsen, R. V., \& Hellekjær , G. O. (2016). The complexity of second language reading: Investigating the L1-L2 relationship . Reading in a Foreign Language , 161-182 .

Brown, G., \& Yule, G. (1983). Discourse Analysis. London: Cambridge University Press.

Chang, Y. (2017). Study on the Discourse Analysis in the Application of English Reading Teaching. 2017 International Conference on Arts and Design, Education and Social Sciences, (pp. 1186-1194).

Cook, G. (1989). Discourse. HongKong: Oxford University Press.

Gee, J. (1999). An Introduction to Discourse Analysis Theory and Method. 11 New Fetter Lane, London EC4P 4EE: Routledge.

Housen, A., Kuiken, F., \& Vedder, I. (2012). Dimensions of L2 performance and proficiency: Complexity, accuracy and fluency in SLA. John Benjamins Publishing.

Jiang, X. (2012). A Study of College English Classroom Discourse. Theory and Practice in Language Studies, 2146-2152.

Landry, K. (2002). Schemata in Second Language Reading. The Reading Matrix, 2, 3.

Maarof, N., \& Yaacob, R. (2011). Meaning-making in the first and second language: reading strategies of Malaysian students. Procedia Social and Behavioral Sciences, 12, 211-223. Retrieved from www.sciencedirect.com

Mustapha, Z. (1995). Schemata as a Reading Strategy. Retrieved from https://files.eric.ed.gov/fulltext/ED415497.pdf

Sattar, S., \& Salehi, H. (2012). The Role of Teaching Reading Strategies in Enhancing Reading Comprehension. International Journal of Current Life Sciences, 4(11), 10922-10928.

Suzuki, K. (1987). Schema Theory: A Basis for Domain Information Design. Paper prepared for the symposium, Application of Schema Theory to Instructional Design, at the Annual Meeting of the Association for Educational Communications and Technology. Atlanta, GA. Retrieved from http://www.gsis.kumamoto-u.ac.jp/ksuzuki/resume/papers/1987a.html

Vivekmetakorn, C. K., \& Thamma, M. (2015). Teacher Questioning from a Discourse Perspective. Language Education and Acquisition Research Network (LEARN) Journal, 8(1), 63-87.

Wilkin, B. (1984). The Role of Adequate Schema for Reading in Good and Poor Readers' Comprehension of Text. Education and Human Development Master's Theses . Retrieved from https://digitalcommons.brockport.edu/ehd_theses/1200 


\section{AUTHOR'S BIO}

Nurtimhar Adil Shahaji is a faculty member of the Education and Liberal Arts department of Southern City Colleges, Zamboanga City, Philippines. He teaches English, Language and Literature, and Communication courses. His research interests are Tausug Linguistics, Language, ELT, and Communication studies. Presently, he is writing his master's thesis at the Western Mindanao State University, Philippines. 